\title{
EL PAPEL DE LAS INSTITUCIONES MICROFINANCIERAS EN EL POSCONFLICTO en Colombia
}

\author{
The Role of Micro-finance \\ INSTITUTIONS IN COLOMBIA'S \\ Post-conflict Period
}

\author{
O PAPEL DAS INSTITUIÇÕES \\ MICROFINANCEIRAS NO \\ PÓS-CONFLITO NA CoLÔMBIA
}

JOSÉ PABLO GRAU-PRADA* 


\section{RESUMEN}

Las instituciones microfinancieras (IMF) en Colombia, que tradicionalmente han sido ejemplo de inclusión financiera, pueden contribuir con los esfuerzos estatales para disminuir los efectos del conflicto armado. Su participación frente a un grupo especial de personas interesadas en reintegrarse a la sociedad las convoca a identificar los retos que surgen de esta labor $\mathrm{y}$ a diseñar productos financieros y no financieros, sin comprometer su patrimonio, acordes con el perfil de los sujetos interesados en reemplazar su actividad como partícipes del conflicto armado por actividades de emprendimiento empresarial. Se defiende la tesis que las IMF, no obstante su carácter privado, pueden apoyar las políticas estatales para el posconflicto mediante una ampliación de la cobertura en la prestación de los servicios microfinancieros en las zonas urbanas y en el sector rural. La metodología que se utilizó hace uso de la descripción y el análisis de elementos teóricos que fundamentan la existencia de las IMF y de las actividades que desarrolla; así como de la recolección y análisis de información del entorno dentro del cual prestan sus servicios.

\section{PALABRAS CLAVE}

Instituciones microfinancieras; microfinanzas; crédito rural; posconflicto; reintegración; desmovilizados; inclusión financiera. 


\section{ABSTRACT}

Micro-finance institutions in Colombia, which traditionally have been examples of financial inclusion, can contribute to the government's efforts to reduce the effects of the armed conflict. Their participation with respect to a special group of individuals who want to rejoin society means they must identify the challenges this effort implies and design financial and nonfinancial products that do not compromise their equity but are in keeping with the profile of the interested parties. The idea, in this respect, is to replace their activity as participants in the armed conflict with activities involving business enterprises. The article defends the thesis that microfinance institutions (MFIs), despite their nature as private entities, can support government policies for the post-conflict period by expanding the coverage of the micro-financial services being provided in urban and rural areas. The methodology that was used involves a description and analysis of theoretical elements that support the existence of MFIs and the activities they develop, coupled with collection and analysis of information about the environment in which they render their services.

\section{KEYWORDS}

Micro-finance institutions; micro-finance; rural credit; post-conflict; reinstatement; demobilized; financial inclusion. 


\section{RESUMO}

As instituições microfinanceiras (IMF) na Colômbia, que tradicionalmente são exemplos de inclusão financeira, podem contribuir com os esforços estatais para diminuir os efeitos do conflito armado. Sua participação ante um grupo especial de pessoas interessadas em se reintegrar à sociedade as convoca a identificar os desafios que surgem desse trabalho e a desenhar produtos financeiros e não financeiros, sem comprometer seu patrimônio, de acordo com o perfil dos sujeitos interessados em substituir sua atividade como partícipes do conflito armado por atividades de empreendimento empresarial. Defende-se a tese de que as IMF, embora de caráter privado, possam apoiar as políticas estatais para o pós-conflito mediante uma ampliação da cobertura na prestação dos serviços microfinanceiros nas áreas urbanas e no setor rural. Utilizaram-se como metodologia a descrição e a análise de elementos teóricos que fundamentam a existência das IMF e das atividades que desenvolvem, assim como a coleta e a análise de informação do contexto no qual prestam seus serviços.

\section{PALAVRAS-CHAVE}

Crédito rural; desmobilizados; inclusão financeira; instituições financeiras; microfinanças; pós-conflito; reintegração. 
Sumario: introducción. 1. Microfinanzas, MeCANismo de Desarrollo. 2. Conflicto ArMADO Y REINTEGRACIÓN ECONÓMICA. 3. EXPERIENCIA INTERNACIONAL: MICROFINANZAS Y POSCONFLICTO. 4. INTERVENCIÓN ESTATAL EN LAS MICROFINANZAS. 5. INCLUSiÓN DEL DESMOVILIZADO a los SERVICIOS OFRECIDOS POR LAS IMF. 6. FUNCIÓN SOCIAL DE LA ACTIVIDAD DESARROLLADA POR LAS IMF. 7. CONCLUSIONES. REFERENCIAS.

\section{INTRODUCCIÓN}

Los intentos de poner fin al conflicto armado en Colombia, que se han concretado en la firma de acuerdos, no son suficientes para que la paz sea sostenible en el tiempo. Se hace necesario que se diseñen políticas públicas que faciliten la inclusión de la población afectada y de los involucrados en el conflicto en las actividades económicas. En el diseño de dichas politicas ha de contemplarse el acceso a servicios microfinancieros como un instrumento que podría contribuir al sostenimiento de la paz, dado que pueden llegar a segmentos de la población con la rapidez y oportunidad que no ofrecen los servicios financieros de la banca tradicional.

En el presente artículo de investigación se analiza el papel de las instituciones microfinancieras (IMF) en el posconflicto y se contextualizan, se exponen y se caracterizan los retos que tales instituciones enfrentan si de manera voluntaria o por disposición legal son vinculadas como organismos de apoyo en la construcción de paz.

Se defiende la tesis de que las IMF, no obstante su carácter privado, pueden apoyar las políticas estatales para el posconflicto mediante una ampliación de la cobertura en la prestación de los servicios microfinancieros en las zonas urbanas y en el sector rural. Los argumentos sobre los cuales descansa esta tesis son: las microfinanzas constituyen un instrumento para llevar servicios financieros y no financieros a personas tradicionalmente excluidas de la banca tradicional; en el mercado colombiano los servicios microfinancieros son ofrecidos por entidades constituidas como organizaciones no gubernamentales, por algunos bancos comerciales y algunas entidades del sector cooperativo; existe una política pública de construcción de paz dentro de la cual no se han incluido las IMF como organismos de apoyo; las IMF permiten la inclusión financiera del desmovilizado; y finalmente, las IMF cumplen una función social que les invita a no permanecer ajenas al contexto en cual operan.

La importancia de este ejercicio investigativo, dentro del marco de la Maestría en Derecho de la Empresa y de los Negocios de la Universidad de La Sabana, radica en que permite integrar dos temáticas que pareciera transitan por senderos diferentes; es una contribución de la academia al manejo del posconflicto, tema de interés nacional en la actualidad; y fortalece el conocimiento y la experiencia del autor en cuanto a las actividades desarrolladas por las IMF. El contenido que se presenta interesa a la comunidad académica, a quienes diseñan los instrumentos para la financiación del posconflicto y a las IMF que pueden encontrar en los retos que aquí se exponen una oportunidad para ampliar la cobertura de los servicios que ofrecen. 
La metodología que se utilizó en la construcción del texto hace uso de la descripción y el análisis de elementos teóricos que fundamentan la existencia de las IMF y de las actividades que desarrollan, así como de la recolección y el análisis de información del entorno dentro del cual prestan sus servicios.

\section{MICROFINANZAS, MECANISMO DE DESARROLLO}

Las microfinanzas forman parte de un movimiento mundial microfinanciero ${ }^{1}$ en el que se reconoce como pionero al Banco Grameen, ${ }^{2}$ que para 2006 daba servicio a más de seis millones de clientes pobres en Bangladesh, junto a sus dos competidores, la Sociedad para el Avance Social y el Comité de Progreso Rural de Bangladesh. ${ }^{3}$ Cuando se inicia el movimiento, específicamente en el Banco Grameen, el punto central no eran las microfinanzas, sino los microcréditos.

Desde hace dos décadas en el ámbito internacional, bajo modalidad de organizaciones no gubernamentales, aparecen establecimientos financieros que mantienen politicas de viabilidad operacional y rentabilidad patrimonial, lo que hizo necesario que contaran con el manejo de una cartera sana, elevada rotación de activos y tasas de interés de colocación altas, propias de créditos de muy baja cuantía y plazo. ${ }^{4}$

Del movimiento internacional financiero forman parte, entre otros, Bancosol, ${ }^{5}$ entidad sin ánimo de lucro, creada en 1984 por un grupo de empresarios bolivianos vinculados al sector microempresarial para apoyar el desarrollo de microempresas en el país, que hoy es una entidad bancaria privada sometida a la normativa de la banca comercial. En el estado de Tamil Nadu, en India, se diseñó un Fondo para el Desarrollo, que se aparta del modelo del banco Grameen, y está dirigido a mujeres pobres de áreas rurales con el fin de contribuir a elevar los ingresos familiares de la población y permitirles que califiquen en un futuro como clientes de los establecimientos de crédito tradicionales. ${ }^{6}$

El desarrollo financiero internacional se complementa con la experiencia de cooperativas de crédito en Georgia, ${ }^{7}$ y la Asociación de Servicios financieros en Sudafrica y Nueva Guinea. La primera experiencia se fundamenta en la creación de 120 cooperativas de crédito rural, que reciben un aporte inicial para gastos de instalación

1 Daryl Collins, Jonathan Morduch y Stuart Rutheford, Las finanzas de los pobres, México, Debate, 2011.

2 Este banco fue fundado por Muhammand Yunus, Premio Nobel de Paz en 2006. La labor está orientada a brindar oportunidades de crédito y a lograr grandes cambios en las comunidades por medio de actividades no financieras que permitan a los grupos consolidarse y ser autosuficientes. De igual manera, por medio del apoyo de grandes corporaciones y gobiernos, Grameen Bank ha logrado generar proyectos de gran escala como la construcción de escuelas o acueductos que transforman las condiciones de los habitantes de la comunidad y les permiten mejorar su calidad de vida.

3 Esta organización es conocida como BRAC, que corresponde a Bangladesh Rural Advancement Committee.

4 Luis Fernando López, "Desarrollo internacional microfinanciero", Contexto (2000), pp. 29-36.

5 En www.bancosol.com.bo

2886 En el trabajo citado en el párrafo anterior, Luis Fernando López Garavito incluye esta experiencia como una manifestación del desarrollo internacional microfinanciero.

7 La república de Georgia formó parte de la Unión Soviética y hoy está organizada como Estado independiente. 
y una donación única para establecer un capital semilla; la segunda experiencia es considerada como una nueva forma de operación financiera que empieza a abrir el camino de un desarrollo microfinanciero apalancado por el sistema bancario tradicional y por la emisión de acciones. ${ }^{8}$

El término microfinanzas hace referencia a la prestación de servicios financieros a personas o grupos cuyo acceso a los sistemas bancarios tradicionales es limitado o del todo inexistente en virtud, por lo general, de su condición socioeconómica. ${ }^{9}$

En la prestación de los servicios financieros existe una serie de programas y mecanismos orientados a suministrar la capacitación técnica y administrativa necesarias para la gestión de la actividad, que normalmente vienen acompañados de financiamiento a pequeña escala, orientado a la implementación, el inicio o la ampliación de negocios.

Sam Daley Harris ${ }^{10}$ reconoce que las microfinanzas trabajan en sinergia con otros mecanismos de desarrollo, tales como aquellos que promueven la salud, la nutrición, la democracia y la educación, y ofrece una mano, no una limosna; además que pueden aliviar el sufrimiento, traer dignidad, hacerse sustentables, e inspirar a otros a dar apoyo.

Uno de los mecanismos tradicionalmente usados en microfinanzas, para cumplir con sus propósitos, es el microcrédito. En Colombia, el microcrédito es una operación de crédito que se otorga a las microempresas, ${ }^{11}$ orientado a apoyar inversiones productivas de desarrollo empresarial y no de consumo. Este microfinanciamiento de corto plazo se otorga a personas vulnerables económicamente; el monto del crédito es relativamente bajo, debido a que se otorga sin garantías reales, como un crédito de confianza, a una tasa de interés superior a la que cobra la banca comercial, lo que permite cubrir los riesgos en que se incurre; los recursos prestados se pagan en periodos cortos, con la ventaja de que los beneficiarios del crédito reciben de la IMF asesoría técnica especializada que incluye visitas para verificar el estado de la actividad empresarial, analizar la operación crediticia y corroborar que el cliente tenga la capacidad y voluntad de pago necesaria para responder por el pago de la obligación.

En Colombia, las entidades prestadoras de servicios en microfinanzas han seguido la tendencia internacional a atender necesidades financieras de individuos y de familias con un perfil muy similar; no se han planteado el reto de atender a otro

8 Idem, p. 33. Las que se han creado cuentan con un capital obtenido a través de la emisión de acciones que la población ha adquirido con sus ahorros; los socios que tengan diez o más acciones asisten a las asambleas y determinan la política crediticia, especialmente en lo relacionado con tasas de interés, montos y plazos.

9 José Luis ARCE, Duodécimo informe sobre el estado de la nación en desarrollo humano sostenible, Costa Rica , 2012.

10 Centro Internacional de Formación Financiera (CIFF), Microfinanzas en países de la OCDE y en vías de desarrollo, Alcalá, Universidad Alcalá de Henares, 2014, p. 50.

11 Aquellas que tienen una planta de personal no superior a 10 trabajadores o activos totales por valor inferior a 500 salarios minimos legales mensuales (Ley 590 de 2000, art. 2). 
segmento de la población que ha formado parte de los grupos al margen de la ley que participaron de manera activa en el conflicto armado en Colombia y que hoy forman parte de programas de reintegración económica.

Las IMF pueden contribuir a reducir o resolver las tensiones del conflicto en tres grados: ${ }^{12}$ mitigación directa, en tanto que el suministro de crédito apoya los procesos económicos que podrían disminuir la presión del conflicto; mitigación indirecta, en la reducción de la pobreza sobre todo en lugares donde el conflicto se origina o fundamenta en la escasez de recursos; mitigación del proceso en el sentido de que incentivan la relación entre los diversos grupos del conflicto y ayudan a reducir el rechazo mutuo.

\section{CONFLICTO ARMADO Y REINTEGRACIÓN ECONÓMICA}

Los orígenes del conflicto armado ${ }^{13}$ en Colombia se ubican principalmente con la aparición en 1964 de las Fuerzas Armadas Revolucionarias de Colombia (FARC), en su inicio como un ejército campesino de inspiración comunista guiado por la idea de reducir las diferencias entre ricos y pobres; han utilizado distintos mecanismos como ataques a ciudades, ataques a oleoductos, secuestros, bloqueo de vías del país y la toma de control de algunas zonas del territorio nacional.

Otro partícipe del conflicto armado colombiano es el Ejército de Liberación nacional (ELN), también denominado Unión Camilista-Ejército de Liberación Nacional (UC-ELN), que se define como de orientación marxista-leninista y pro Revolución cubana, como fundamentos filosóficos para denunciar y promover la solución de necesidades de la población frente a la explotación nacional e internacional. ${ }^{14}$

A finales de la década de los noventa surge un tercer partícipe el conflicto bajo el nombre Autodefensas Unidas de Colombia (AUC), y, guiadas por su intención de combatir a las guerrillas comunistas, principalmente a las FARC y al narcotráfico como financiador de la guerrilla, fundamentan su actuación en el abandono estatal y su incapacidad para contrarrestar las actuaciones de organizaciones al margen de la ley y las consecuencias de su accionar militar y politico.

Las actuaciones de los tres principales actores del conflicto motivaron a que el Estado colombiano diseñara estrategias para lograr el desarme, la desmovilización y la reintegración de los grupos armados ilegales, a saber: en primer lugar, se partió de dar facultades al Gobierno nacional para negociar con los grupos armados ilegales y para concederles beneficios jurídicos por conductas constitutivas de delitos politi-

12 Stacy Heen, "The role of microcredit in conflict and displacement mitigation: A case study in Cameroon”, The Fletcher Journal of International Development (2004), pp. 31-50.

13 Por conflicto armado se entiende el conjunto específico de acciones y actores armados caracterizado por el uso de ciertas armas y medio de guerra en un área geográfica del país, en el que se concreta la dificultad para separar los fenómenos de violencia generalizada y delincuencia común, del accionar de los actores armados. Esta definición se construye con base en la Sentencia C-225 de la Corte Constitucional colombiana, de mayo 18 de 1995. M. P. Alejandro Martínez Caballero.

14 Comisión Histórica del Conflicto y sus Víctimas, Contribución al entendimiento del conflicto armado en Colombia, 2015. 
cos a miembros de organizaciones que demostraran su voluntad de reincorporarse a la vida civil, ${ }^{15}$ y en segundo lugar, se diseñaron procedimientos y requisitos para la desmovilización y reintegración, y se elimina el carácter político de las organizaciones ilegales como condición para negociar, situación que legitimó al Gobierno nacional para iniciar negociaciones con los grupos de autodefensas. ${ }^{16}$

La politica estatal diseñada hasta ese momento era de corto plazo, desarrollaba actividades de tipo asistencial y humanitario dentro de una política de reincorporación diseñada y coordinada por el Ministerio del Interior y de Justicia con el apoyo de la oficina del Alto Comisionado para la Paz, ${ }^{17}$ dentro del programa de reincorporación a la vida civil.

El incremento de la población desmovilizada, y la necesidad de crear las condiciones para obtener una desmovilización total de los grupos armados ilegales y de diseñar estrategias para la consolidación de la paz, justificó la creación, en septiembre de 2006, de la Alta Consejería Presidencial para la Reintegración Social y económica de personas y grupos alzados en armas, ${ }^{18}$ con la que se mantiene la intención estatal de recibir dos tipos de población desmovilizada. De una parte, los desmovilizados colectivos, que se entregan como grupo, previa negociación con la oficina del Alto Comisionado para la paz, y de otra parte, los desmovilizados individuales que se entregan individualmente a través del Programa de Atención Humanitaria al desmovilizado (PAHD), ejecutado por el Ministerio de Defensa, que se encarga de certificar la condición de desmovilizado.

El desmovilizado, ya sea colectivo o individual, entra en una etapa de reintegración, a cargo de la Alta Consejería Presidencial para la Reintegración (ACPR), encargada de coordinar, asesorar y ejecutar con entidades públicas y privadas la ruta de reintegración.

Con el Plan Nacional de Desarrollo 2006-2010, "Estado comunitario: desarrollo para todos", se formula una politica de reintegración social y económica (PRSE), con visión de largo plazo, orientada a promover la incorporación efectiva del desmovilizado con voluntad de paz y de su familia a las redes sociales del Estado y a las comunidades receptoras. La política busca asegurar la superación de su condición a través de distintos medios : a) la integración de la oferta social y económica del Estado; b) el acompañamiento para incrementar la probabilidad de que las intervenciones mejoren las condiciones de calidad de vida de la población desmovilizada y de sus familias; y c) la construcción de un marco de corresponsabilidad que, por un lado, apoye al desmovilizado a regresar y convivir constructivamente en su entorno familiar y comunitario, y por el otro, lo comprometa a él y a sus dependientes con la superación de su situación y la permanencia en la legalidad. ${ }^{19}$

15 Ley 418 de 1997, Ley 548 de 1999, Ley 782 de 2002 y Ley 1106 de 2006.

16 Ley 782 de 2002, reglamentada mediante los decretos 128 de 2003, 3360 de 2003, 2767 de 2004 , 1262 de 2004 y 395 de 2007.

17 Creado desde 1983 mediante decretos 240 y 2560.

18 Decreto 3043 de septiembre de 2006.

19 Tomado de documento Conpes 3554 titulado "Política nacional de reintegración social y económica para personas y grupos armados ilegales”. Versión aprobada, diciembre 1 de 2008. 
El Plan Nacional de Desarrollo 2010-2014, "Prosperidad para todos", se trazó como uno de los ejes estratégicos la consolidación de la paz. Consolidar la paz significa garantizar el Estado de derecho en todo el territorio nacional, la seguridad, la observancia plena de los derechos humanos, y el funcionamiento eficaz de la justicia. ${ }^{20}$ Durante este periodo se aprueba el marco jurídico para la paz, norma que implicó una reforma constitucional y otorgó herramientas para la negociación con los grupos armados; igualmente, el Gobierno colombiano firma con las FARC un acuerdo en La Habana para abrir un diálogo en torno a buscar soluciones para el manejo del conflicto.

El Plan Nacional de Desarrollo 2014-2018, "Todos por un nuevo país”, incluye como ejes la paz, la equidad y la educación. Estos tres ejes fueron considerados como un círculo virtuoso en los siguientes términos: una sociedad en paz puede focalizar sus esfuerzos en el cierre de brechas y puede invertir recursos para mejorar la cobertura y calidad de su sistema educativo. Una sociedad equitativa es aquella sin marcadas diferencias socioeconómicas, que permite la convivencia pacífica y facilita las condiciones de formación en capital humano. Finalmente, una sociedad educada cuenta con una fuerza laboral calificada, sin grandes diferencias de ingresos y con ciudadanos que resuelven sus conflictos sin recurrir a la violencia. De forma más simple: la paz favorece la equidad y la educación, la equidad propicia la paz y la educación, y la educación genera condiciones de paz y equidad. ${ }^{21}$

El conflicto armado afecta la infraestructura del país e incide de manera negativa en el crecimiento económico, dado que los enfrentamientos violentos traen como consecuencia la destrucción del capital físico y humano, afectan las decisiones de inversión e impiden el ejercicio de actividades comerciales. La existencia de instituciones financieras y microfinancieras contribuye a contrarrestar los efectos negativos del conflicto en el ámbito económico, en la medida en que asigna capital a proyectos productivos y contribuye a mejorar el uso de los factores de producción, genera empleo y amplía la oferta de bienes y servicios.

Uno de los instrumentos utilizados para incorporar a la sociedad a los partícipes del conflicto es la reintegración económica que tiene como objetivo que el desmovilizado sea autónomo en la generación de ingresos de manera sostenible en la legalidad. ${ }^{22}$ Así, el desmovilizado tendrá la posibilidad de acceder a programas de financiación de negocios mediante la presentación de un proyecto, o adherirse a iniciativas productivas que los organismos estatales diseñen con otras instituciones públicas y el sector privado.

20 Plan Nacional de Desarrollo 2010-2014, "Prosperidad para todos”, Capítulo 5: Consolidación de la paz.

21 Tomado de Bases del Plan Nacional de Desarrollo 2014-2018, en https://colaboracion.dnp.gov. co/CDT/Prensa/Bases\%20Plan\%20Nacional\%20de\%20Desarrollo\%202014-2018.pdf. Fecha de consulta: 15 de noviembre de 2015.

292 Angie Juliet CASTILL RAMíREz, Arlley MoREno PARGa, La reintegración económica de personas desmovide capacidades, Bogotá, Corporación Universitaria Minuto de Dios, 2013. 
En el caso colombiano, el estudio de los proyectos de negocio y emprendimiento está a cargo de la Agencia Colombiana para la Reintegración (ACR), que analiza la viabilidad técnica y financiera de los proyectos, y durante la etapa de estudio brinda formación empresarial y técnica permanente a quienes lo requieran. Los recursos para la financiación de las iniciativas de negocios se hacen a través del Programa de Apoyo Financiero (PAF), integrado por un programa de apoyo crediticio, a través del Fondo de Inversión para el Beneficio Social (FIBS), y por un programa de capital semilla, con el cual las personas en proceso de reintegración pueden financiar y completar los recursos necesarios para su proyecto productivo. ${ }^{23}$

El apoyo financiero al desmovilizado se ha diseñado a partir de planes, programas e instrumentos estatales, que bien podrian apoyarse en las entidades de microfinanzas existentes en el mercado colombiano creadas para atender un segmento de la población usualmente llamado microempresario.

Las IMF ayudan en el posconflicto a través de los siguientes mecanismos: el estímulo al empoderamiento de los miembros de la comunidad para establecer compañias propias y recuperar la confianza mutua; el incentivo a la reintegración de afectados y actores del conflicto a través de créditos asociativos. ${ }^{24}$

\section{EXPERIENCIA INTERNACIONAL: MICROFINANZAS Y POSCONFLICTO}

La propuesta que se realiza en esta investigación de ver en las IMF un organismo que puede apoyar los procesos de construcción de paz ${ }^{25}$ en Colombia no es algo novedoso en el mundo. En este apartado se presenta una reseña de la vinculación de las IMF en tales procesos que sirve como referente para nuestro propósito. El estudio de las microfinanzas en el despertar de los conflictos en Uganda ${ }^{26}$ mostró que el papel de las IMF produce mejores resultados cuando las condiciones sociales alteradas por el conflicto se han estabilizado. En este país, las IMF no se apresuraron a ofrecer servicios en las zonas aún afectadas por el conflicto; reconocieron la necesidad de esperar algún tiempo hasta que percibieran un cambio en las condiciones sociales.

Igualmente, el estudio destaca que la fuente de los recursos de crédito para la financiación del conflicto será estatal y su colocación requerirá un análisis y com-

23 Consejo Nacional de Política Económica y Social, Documento Conpes 3554. Política Nacional de integración Económica y Social para Personas y Grupos Armados Ilegales, Bogotá, 2008.

24 Dairo Estrada, Lisset Venegas y Paula Zuleta, Desarrollo económico, crédito rural y conflicto armado en Colombia, Bogotá, Citi Foundation, Finagro y Asomicrofinanzas, 2015.

25 La expresión "construcción de paz" se utiliza con el alcance trazado por las Naciones Unidas en el informe de 1992 titulado "Un programa de paz". En este documento se definió como "las medidas destinadas a individualizar y fortalecer estructuras que tiendan a reforzar y consolidar la paz a fin de evitar una reanudación del conflicto”, Naciones Unidas, 1992.

26 Jessica JAcoBson, Uganda: The provision of microfinance in the wake of conflict, Baltimore, Johns Hopkins University Press, 2001. 
prensión local de riesgos, lo que conduce a diseñar estrategias para minimizarlos, así la expansión de los servicios financieros tendrá lugar en aquellos sitios que se identifiquen como más seguros. Por último, afirma que el éxito de las IMF en el posconflicto depende en gran medida del compromiso estatal en la asignación de recursos y en los esfuerzos de reconstrucción social.

De manera general, en Uganda se demostró que los pobres, incluso en un entorno posterior a un conflicto, ${ }^{27}$ son financiables al punto de que las IMF pueden obtener beneficios por los servicios prestados a ellos.

Un estudio sobre el apoyo de las IMF en la etapa de posconflicto en Camboya, Angola, Mozambique y Ruanda ${ }^{28}$ mostró que la falta de un marco legal no impidió el desarrollo de las actividades microfinancieras en el posconflicto; las actividades comerciales que fueron financiadas por IMF fueron la principal fuente de ingresos familiares; la transición hacia la paz se produce de manera diferente según el lugar donde se utilicen las microfinanzas como instrumento para el manejo del conflicto; la situación política afecta el desarrollo de las microfinanzas; las actividades microfinancieras son ofrecidas por organizaciones no gubernamentales basadas en la estrategia ensayo y error; finalmente, el estudio permitió reconocer que existen obstáculos para el sostenimiento de las IMF entre los cuales se encuentra la inseguridad, el recurso humano y las dificultades en los desplazamientos.

La participación de las IMF en el posconflicto en Liberia ${ }^{29}$ demostró que las microfinanzas pueden aplicarse con éxito bajo las siguientes condiciones: i) condiciones necesarias: estabilidad política; suficiente actividad económica que acceda a servicios crediticios; clientela relativamente estable; ii) condiciones deseables: existencia de una banca tradicional; el uso de metodologías individuales y grupales para la asignación de créditos; estabilidad macroeconómica. El estudio destaca que el sector financiero es altamente excluyente por las condiciones y los requisitos que exige para acceder a los servicios financieros.

\section{INTERVENCIÓN ESTATAL EN LAS MICROFINANZAS}

Las instituciones que incursionan en el mercado de microfinanzas en Colombia son de distinta naturaleza: un primer grupo está integrado por entidades constituidas como organizaciones no gubernamentales con capital privado y objeto social exclusivo relacionado con actividades de microfinanzas; un segundo grupo está integrado por bancos comerciales que han incluido dentro de su portafolio de ser-

27 Después de la guerra, la economía de Uganda se caracterizó por una población móvil, bajos niveles de ahorro, inflación, desconfianza, pobreza, inseguridad, sistema bancario deficiente, regulación que no funcionaba, aumento de la dependencia del sector informal y un alto nivel de incertidumbre.

28 Tamsin Wilson, Microfinance during and after armed conflict: Lesson from Angola, Cambodia, Mozambique and Ruanda, Springfield, 2002, en http://www.springfieldcentre.com/wp-content/ uploads/2012/10/sp0202.pdf. Fecha de consulta: 30 de noviembre de 2015.

294 John TucKer, Microfinance development in Liberia, 2004, en http://www.microfinancegateway. $\mathrm{org} / \mathrm{sites} / \mathrm{default} /$ files /mfg-en-paper-microfinance-development-in-liberia-an-initial-assessment-2004.pdf. Fecha de consulta: 27 de noviembre de 2015. 
vicios productos dirigidos al sector microempresarial; y un tercer grupo, entidades del sector solidario de la economía, que han sido constituidas como cooperativas que incluyen en su portafolio productos guiados a la microempresa.

Las entidades que operan en el mercado colombiano se presentan en la siguiente tabla: ${ }^{30}$

Tabla 1. Entidades que operan en el mercado colombiano

\begin{tabular}{|l|l|l|}
\hline Entidades constituidas como ONG & Bancos comerciales & Entidades del sector solidario \\
\hline Actuar Atlántico & Bancamia & Comerciacoop \\
\hline Actuar Caldas & Banco de Bogotá & Confiar \\
\hline Actuar Quindio & Banco Caja Social & Congente \\
\hline Contactar & Banco Mundo Mujer & Cooperativa Uniminuto \\
\hline Corporación de Microcrédito AVAL & Banco WWB & Crearcoop \\
\hline Eclof & Bancolombia & Financiera Comultrasan \\
\hline Encumbra & Davivienda & Microempresas de Colombia \\
\hline Express Microfinanzas & & \\
\hline Fundación Mario Santo Domingo & & \\
\hline Fundación Coomeva & & \\
\hline Fundación Amanecer & & \\
\hline Fundación de la Mujer & & \\
\hline Fundación el Alcaraván & & \\
\hline Fundación Emprender & & \\
\hline Fundescat & & \\
\hline Fundesmag & & \\
\hline Garantías Comunitarias & & \\
\hline Interactuar & & \\
\hline
\end{tabular}

Fuente: elaboración propia con datos tomados de Asomicrofinanzas, en www.asomicrofinanzas.com.co

El Estado colombiano interviene en la actividad financiera mediante la regulación ${ }^{31}$ e inspección, vigilancia y control. ${ }^{32}$ Las entidades del primer grupo tienen libertad para desarrollar las actividades que constituyan su objeto, conforme al acto

30 Datos tomados de www.asomicrofinanzas.com.co. Fecha de consulta: 13 de octubre de 2015.

31 La regulación de la actividad financiera responde al siguiente modelo: el Congreso de la República expide la ley marco, en la cual se fijan objetivos y criterios a los que debe someterse el Gobierno nacional para regular las actividades financiera, bursátil, aseguradora y cualquiera otra relacionada con el manejo, aprovechamiento e inversión de los recursos captados del público (art. 150 núm. 19 lit d, CP).

32 La Constitución Política colombiana atribuye al presidente de la república la obligación de ejercer, de acuerdo con la ley, la inspección, vigilancia y control sobre las personas que realicen actividades financieras, bursátiles, aseguradoras y cualquier otra relacionada con el manejo, aprovechamiento o inversión de recursos captados del público. Asimismo, sobre las entidades cooperativas y las sociedades mercantiles (art. 189 núm. 24). 
constitutivo de la organización y a sus reformas estatutarias. No están sometidas a inspección, vigilancia y control debido a que no captan recursos del público, colocan créditos a través de la propia autosuficiencia financiera y de préstamos que adquieren de banca nacional e internacional. Las del segundo grupo, se someten a la regulación estatal, ${ }^{33}$ y a la inspección, vigilancia y control de la Superintendencia Financiera de Colombia, ${ }^{34}$ y finalmente, las del tercer grupo también someten su actividad a la regulación estatal, ${ }^{35}$ con la diferencia de que es la Superintendencia de Economía solidaria la que ejerce la función de inspección, vigilancia y control. En Colombia existe un marco legal para el microcrédito y no para las microfinanzas. Este marco legal ha creado figuras relacionadas con:

a. Sistema de microcrédito. ${ }^{36}$ Se crea un producto financiero denominado microcrédito y se fija como monto máximo por operación el valor equivalente a veinticinco salarios minimos legales mensuales vigentes, el cual debe estar dirigido a microempresas entendidas como unidad económica que tiene activos totales hasta de 500 salarios minimos legales mensuales vigentes y menos de 10 empleados.

b. Creación del Consejo Superior de la Microempresa, ${ }^{37}$ con el fin de asegurar la formulación y adopción de políticas públicas generales, transversales, sectoriales y regionales de fomento y promoción empresarial para las micro, pequeñas y medianas empresas, con el propósito de generar empleo y crecimiento económico sostenido.

c. Regulación sobre riesgo crediticio, calificación de cartera y provisiones. ${ }^{38}$ En el año 2001, la entonces Superintendencia Bancaria expide la Circular Externa 050, mediante la cual se regula.

d. Crea el microcrédito inmobiliario ${ }^{39}$ para la financiación de vivienda a menos de cinco años sin garantía hipotecaria y establece la posibilidad de cobro de una comisión para retribuir los mayores costos administrativos.

e. Banca de oportunidades. ${ }^{40}$ Se crea una banca de oportunidades como un programa de inversión con el fin de promover el acceso al crédito y los demás servicios financieros a las familias de menores ingresos, micro, pequeñas y medianas empresas y emprendedores. Para cumplir con este fin, se permite que el Ministerio de Hacienda y Crédito Público suscriba un contrato con el

33 Decreto 663 de 1993.

34 Decreto 4327 de 2005.

35 Ley 79 de 1998, reglamentada por el Decreto 468 de 1990.

36 Ley 590 de 2000, modificada por Ley 905 de 2004.

37 Ley 590 de 2000, modificada por Ley 905 de 2004, reglamentado por los acuerdos 001 de 2012 y 002 de 2013 expedidos por el presidente de dicho consejo.

38 Circular Externa 050 de 2001 de la Superintendencia Financiera de Colombia.

29639 Artículo 95 de la Ley 795 de 2003. Esta figura se insertó mediante esta ley pero fue derogada por la Ley 1151 de 2007. Se cita como referente para mostrar el desarrollo legal de figuras relacionadas con las microfinanzas. 
Banco de Comercio Exterior de Colombia S.A. (Bancoldex), para la administración de los recursos que se destinen para el financiamiento del programa de Inversión Banca de las Oportunidades.

f. Fondo de Financiamiento para el sector Agropecuario (Finagro).$^{41}$ Creado desde 1990 como una sociedad de economía mixta del orden nacional, constituida como sociedad anónima, que opera como establecimiento de crédito vinculado al Ministerio de Agricultura y Desarrollo Rural. Su propósito es contribuir al desarrollo integral, competitivo y sostenible del sector rural, facilitando el acceso al financiamiento y a los demás instrumentos de apoyo establecidos en la política pública.

Este marco legal pone de presente una politica estatal que reconoce la existencia de microcréditos, sin incluir a las IMF constituidas como organizaciones no gubernamentales con capital privado, bajo la normativa propia de la banca tradicional. ${ }^{42}$ Esta tendencia legislativa no es un obstáculo para que ellas contribuyan con la financiación del posconflicto, por el contrario, les permite un amplio margen de actuación sobre todo en el diseño de productos financieros.

A diferencia de los organismos que forman parte del sistema financiero y asegurador colombiano, ${ }^{43}$ esto es, los establecimientos de crédito, ${ }^{44}$ las sociedades de servicios financieros, ${ }^{45}$ las sociedades de capitalización, ${ }^{46}$ las entidades aseguradoras, los intermediarios de seguros, que solo pueden desarrollar las actividades que el Estado mediante regulación les autorice, las IMF constituidas como organizaciones no gubernamentales pueden desarrollar cualquier tipo de actividades, y diseñar los productos financieros conforme a su política interna. Esta es la principal fortaleza que el derecho colombiano ofrece para que el Estado se apoye en las IMF en el proceso de construcción de paz.

41 En www.finagro.com.co

42 La banca tradicional está sometida a un régimen legal especial contenido hoy en el Decreto 663 de 1993, en el cual se regula las etapas para su formación; se fijan reglas sobre su funcionamiento; se exige autorización estatal para iniciar actividades y se impone la tipología de instituciones financieras, entre otras exigencias.

43 Véase tabla 1 de este artículo.

44 Su función principal consiste en captar en moneda legal recursos del público en depósitos, a la vista o a término, para colocarlos nuevamente a través de préstamos, descuentos, anticipos u otras operaciones activas de crédito. No se distingue el perfil de sus clientes, por lo que tienen libertad para segmentar su mercado. Ver artículo 2 del Decreto 663 de 1993. Son establecimientos de crédito los bancarios, las compañias de financiamiento, las corporaciones financieras y las cooperativas financieras.

45 De este grupo forman parte las sociedades fiduciarias, los almacenes generales de depósito, las sociedades administradoras de Fondos de Pensiones y de cesantías, y las sociedades de intermediación cambiaria y de servicios financieros especiales, las cuales tienen por función la realización de las operaciones previstas en el régimen que regula su actividad, que complementan la captación y colocación de dinero en el mercado. Véase artículo 3 del Decreto 663 de 1993.

46 Están encargadas de estimular el ahorro mediante la constitución, en cualquier forma, de capitales determinados, a cambio de desembolsos únicos o periódicos, con posibilidad o sin ella de reembolsos anticipados por medio de sorteos. 
El diseño de productos financieros para el posconflicto y la prestación de servicios podrá apoyarse en figuras jurídicas e instrumentos ya existentes en el derecho colombiano, independientemente del área del derecho a la cual pertenezcan. Entre ellas se reseña:

a. Reconocimiento de la personalidad jurídica e igualdad. El derecho colombiano reconoce como persona a todo individuo de la especie humana, cualquiera sea su edad, sexo, estirpe o condición, ${ }^{47}$ y les garantiza recibir la misma protección y trato de las autoridades, así como gozar de los mismos derechos, libertades y oportunidades sin ninguna discriminación. ${ }^{48}$ Bajo esta directriz, el desmovilizado no puede ser excluido de los servicios financieros que se ofrecen a cualquier individuo de la especie humana que no ha participado en el conflicto armado en calidad de combatiente.

b. Aptitud para adquirir derechos y contraer obligaciones. Consecuencia del reconocimiento de la personalidad jurídica, el derecho colombiano, como un atributo de la personalidad, reconoce a cualquier individuo la capacidad jurídica para expresar actos y declaraciones de voluntad, siempre y cuando sea legalmente capaz, exprese su consentimiento exento de error, fuerza o dolo; que su declaración de voluntad recaiga sobre un objeto lícito y tenga causa lícita. ${ }^{49}$ La condición de excombatiente o desmovilizado no implica una limitación o una falta de capacidad para suscribir contratos y títulos valores, necesarios para que los interesados en reintegrarse a la sociedad accedan a servicios financieros.

c. Existe un marco legal sobre garantías reales y garantías personales. El derecho civil colombiano ofrece como figuras utilizables para la cobertura del riesgo del incumplimiento la hipoteca, ${ }^{50}$ la posibilidad de constituir garantias mobiliarias, ${ }^{51} \mathrm{y}$ las figuras de la fianza ${ }^{52} \mathrm{y}$ el aval. ${ }^{53}$ Mediante estos instrumentos las IMF encontrarán un respaldo a las obligaciones contraídas por los excombatientes, en la medida en que ellos o un tercero puedan ofrecer y constituir la garantía.

47 Artículo 74, Código Civil colombiano.

48 Artículo 13, Constitución Política de Colombia.

49 Artículos 1502 a 1526 del Código Civil.

50 Es un derecho de prenda constituido sobre inmuebles que no dejan de permanecer en poder del deudor. La regulación de hipoteca está contenida hoy en los artículos 2432 a 2457 del Código Civil.

51 Ley 1676 de 2013. Mediante esta ley se promueve el acceso al crédito y se dictan normas sobre garantías mobiliarias. La expresión garantía mobiliaria es relativamente nueva en Colombia, y conforme a la citada ley, se utiliza para referirnos a toda operación que tenga como efecto garantizar una obligación con los bienes muebles del garante e incluye, entre otros, aquellos contratos, pactos o cláusulas utilizados para garantizar obligaciones respecto de bienes muebles, entre otros la venta con reserva de dominio, la prenda de establecimiento de comercio, las garantías y transferencias sobre cuentas por cobrar, incluyendo compras, cesiones en garantía, la consignación con fines de garantía y cualquier otra forma contemplada en la legislación colombiana.

52 Conforme al artículo 2361 del Código Civil, la fianza es una obligación accesoria, en virtud de la cual una o más personas responden por una obligación ajena, comprometiéndose con el acreedor a cumplirla en todo o en parte, si el deudor principal no la cumple.

$53 \mathrm{El}$ aval es una garantía personal para respaldar obligaciones que surgen de la firma de documentos considerados por la legislación colombiana como títulos valores: letra de cambio, cheque, pagaré, factura de venta, bonos, certificados de depósito de mercancías, bonos de prenda, carta de porte, conocimiento de embarque, aceptaciones bancarias. 
d. Tipicidad y atipicidad contractual. Los servicios financieros que la IMF diseñen tendrán como fundamento el principio de la autonomía de la voluntad, esto significa que podrán utilizar instrumentos tradicionales regulados por la ley civil o comercial o diseñar cualquier tipo de figura contractual que sea acorde con la necesidad, cobertura, complejidad y naturaleza del producto o servicio financiero que se va a ofrecer.

Las figuras tradicionalmente usadas, conocidas como contratos típicos, dependen del servicio financiero; las figuras jurídicas existentes en el derecho colombiano son contratos de depósito, para las instituciones que captan dinero, y el contrato de mutuo, para las colocaciones de dinero.

El contrato de depósito será el instrumento jurídico que regulará la relación entre la IMF que capte dinero y su cliente (desmovilizado). Aquella recibirá el dinero y asumirá la obligación de devolverlo a su cliente, en una fecha fija ${ }^{54}$ o determinable, o en el momento en que el cliente depositante lo solicite. ${ }^{55}$

De otra parte, para las colocaciones de recursos monetarios, la figura jurídica por utilizar será el contrato de mutuo, entendido como un préstamo de consumo mediante el cual una de las partes entrega a otra cierta cantidad de cosas fungibles, en este caso, dinero, con cargo de restituir otras del mismo género y calidad. ${ }^{56} \mathrm{El}$ plano teórico no siempre coincide con el práctico, toda vez que en las IMF y, en general, la banca tradicional, sustituye esta figura contractual por la firma de un pagaré. ${ }^{57}$

El uso de estas figuras tradicionales no impide que las IMF puedan definir el contenido de cada contrato en particular, en asuntos no mencionados por el derecho privado colombiano. Podrá, con base en la autonomía de la voluntad, crear las reglas particulares de derecho que van a regular la relación con el cliente, según el servicio financiero por ofrecer.

Encontramos que el ámbito de la atipicidad contractual será el que caracterice la prestación de servicios distintos al microcrédito, lo que traerá consigo una ampliación de cobertura de servicios financieros y exigirá insertar cláusulas especiales acorde con el perfil de cada cliente.

e. Regulación del habeas data financiero. La Constitución Politica colombiana reconoce el derecho fundamental de toda persona a conocer, actualizar y

54 En este caso estamos frente a un depósito a término regulado en los artículos 1393 a 1395 del Código de Comercio.

55 Hacemos referencia a la modalidad de depósitos a la vista, de los que forman parte los depósitos en cuenta corriente bancaria y depósitos de ahorros. Su regulación puede consultarse en los artículos 1382 a 1392 y 1396 a 1398 del Código de Comercio. Cabe advertir que el depósito en cuenta corriente bancaria es un producto financiero que solo puede ser ofrecido por los bancos comerciales conforme al artículo 2 del Decreto 663 de 1993.

56 Artículos 2221 a 2235 del Código de Comercio.

57 Artículos 709 a 711, Código de Comercio. En este documento se plasma una manifestación unilateral de voluntad otorgada por el excombatiente, mediante la cual se compromete a devolver a la IMF la suma de dinero recibida por él en calidad de préstamo. 
rectificar informaciones que se hayan recogido sobre ellas en bancos de datos y en archivos de entidades públicas. ${ }^{58} \mathrm{El}$ desarrollo legal de este mandato constitucional, ${ }^{59}$ que es aplicable a todos los datos personales financieros, crediticios, comerciales y de servicios registrados en un banco de datos, permitirá a la IMF, como a cualquier banco tradicional, previa autorización del titular del dato, consultar la historia crediticia del excombatiente.

Estos instrumentos jurídicos, sumados a los reglamentos y a la política de inclusión particular diseñados por cada IMF, le permitirán al excombatiente vincularse a fin de contribuir al mejoramiento de la calidad de vida, y le darán herramientas para la construcción de empresa. De manera que el marco jurídico para la paz solo requerirá vincular a las IMF y regular las fuentes de recursos para contribuir en el posconflicto.

\section{INCLUSIÓN DEL DESMOVILIZADO A LOS SERVICIOS OFRECIDOS POR LAS IMF}

Las IMF incluyen en sus politicas las condiciones o los requisitos que las personas naturales o jurídicas deben cumplir para acceder a los productos y servicios financieros que ofrecen, los cuales, generalmente, cubren necesidades de financiamiento e inversión.

El cliente de la IMF es la persona natural o jurídica que desarrolla actividades empresariales, agropecuarias, industriales, comerciales o de servicio, que tenga una planta de personal no superior a diez trabajadores o activos totales por valor inferior a 500 salarios minimos legales mensuales, que desarrolle actividades en zonas urbanas o rurales.

Cada IMF tiene libertad para crear nuevos productos o servicios financieros; definir el perfil de sus clientes; fijar los criterios mínimos de aceptación; formular los criterios de evaluación de sus clientes; fijar las características de los créditos; imponer restricciones; exigir actualización de información tanto en la fase de estudio del crédito como el control de la inversión, y fijar la metodología de análisis de riesgo crediticio.

Dentro de los criterios mínimos de aceptación de un cliente los instrumentos usados son la edad, el número de empleados, la antigüedad en el desarrollo de la actividad económica; la ubicación; los reportes en las centrales de riesgos y en el Sistema de Administración del Riesgo de Lavado de Activos y Financiación del Terrorismo (Sarlaft), y la existencia de garantias minimas exigidas por la IMF.

En este diseño institucional, una persona natural que participó en el conflicto armado como combatiente y que tenga el estatus de desmovilizado no cumple con

58 Artículo 15, Constitución Política de Colombia.

59 Ley 1266 de 2008. 
los criterios mínimos de aceptación. En Colombia desmovilizado es aquel que por decisión individual abandona voluntariamente sus actividades como miembro de organizaciones armadas al margen de la ley, esto es, grupos guerrilleros y grupos de autodefensa, y se entregue a las autoridades de la república. ${ }^{60}$

El desmovilizado no cumpliría con tales criterios debido a que su diseño ha sido formulado para apoyar empresas o ideas de negocios dentro de un enfoque de fomento de la cultura del emprendimiento. Las IMF no han incluido dentro del diseño de sus politicas la posibilidad de contribuir en los procesos de reintegración, de formación de nuevos sujetos sociales, de ser agentes que participen en la construcción de paz y sean un mecanismo que permita incorporar a esa categoría de personas a un proyecto de vida seguro, digno y productivo. "Para atender este reto, las IMF han de comprender que la desmovilización individual conlleva una ruptura con la estructura militar a la cual se perteneció, y la decisión de marginarse del conflicto armado es totalmente personal e implica la búsqueda y el interés por un nuevo futuro desde la civilidad". ${ }^{61}$

Si bien los desmovilizados no son excluidos de manera expresa del acceso a servicios financieros ya tradicionales, o los prestados por IMF, su sometimiento a un estudio de crédito no produce el mismo resultado cuando se evalúa crediticiamente a una persona a quien no se le ubica en esa categoria. Esto ocurre porque al no tener mayores oportunidades de integración en espacios laborales, los participantes presentan una alta vulnerabilidad económica. ${ }^{62}$

La esencia de las microfinanzas es la inclusión financiera. En esa medida, al menos en el plano teórico, el desmovilizado no encuentra cerrada la posibilidad de recibir los servicios ofrecidos por ellas. La identificación y administración del riesgo de incumplimiento, la metodología utilizada para el diseño de los productos financieros, las fuentes de recursos para diseñar productos que beneficien al desmovilizado, los instrumentos por utilizar ante la mora en el pago de las obligaciones, los mecanismos de cobertura de riesgos y los incentivos para la institución de microfinanzas son las variables para estudiar la posibilidad de que estas organizaciones sean un instrumento de apoyo a la política estatal de reintegración económica.

La entidad de microfinanzas, al ofrecer sus productos y servicios a cualquier modalidad de público, enfrenta un riesgo de crédito o de incumplimiento en el pago de las obligaciones contraídas por su cliente. Este es el riesgo de contraparte en los distintos tipos de operaciones que realiza una institución bancaria. Esta modalidad de riesgo se asocia con las pérdidas patrimoniales ocasionadas por el incumplimiento en el pago de una obligación dineraria, que produce como efecto

\footnotetext{
60 Artículo 2, Decreto 128 de 2003.

61 Mauricio Acosta, Experiencias de jóvenes excombatientes en proceso de reintegración a la vida civil en Bogotá D.C., Bogotá, Alcaldía Mayor de Bogotá, Fundación Friederich Eberth (Fescol), 2007.

62 Dylan Herrera y Paola GonzÁlez, "Estado del arte del DDR en Colombia frente a los estándares internacionales en DDR”, Colombia Internacional (2013), pp. 272-302.
} 
un deterioro en la calidad de la cartera, e implica un deterioro de los activos y en la fuente de pago de los pasivos que toma del público. ${ }^{63}$

Los indicadores para el estudio del cliente no varian si la cobertura de los servicios ofrecidos se amplía a los desmovilizados. De esta forma, las características del cliente, su nivel de pobreza, el grado de informalidad de su negocio, la lejanía de su ubicación y la inestabilidad de su ocupación incrementan los costos y el riesgo de prestar a cualquier cliente de las instituciones de microfinanzas. Estas, para el adecuado manejo y administración del riesgo, se guian por las directrices de la banca tradicional, y en el manejo y administración del riesgo se basan en el conocimiento del sujeto de crédito o contraparte, de su capacidad de pago y de las características del contrato que se va a celebrar entre las partes, para lo cual incluyen las condiciones financieras del préstamo, las garantias, las fuentes de pago y las condiciones macroeconómicas a las que pueda estar expuesto. ${ }^{64}$

Ante el riesgo de incumplimiento existen instrumentos jurídicos tradicionales que suponen que el interesado en ofrecer garantizar un crédito tiene en su patrimonio bienes inmuebles (hipoteca) o muebles (garantía mobiliaria) suficientes, ya para respaldar el monto de la suma adeudada o para transferirlos a una fiduciaria a fin de que integre un patrimonio autónomo con el mismo propósito; el modelo tradicional también supone que tiene unos niveles de liquidez y solvencia que puede conseguir que personas naturales o juridicas, sin comprometer en particular un bien, con su firma respalden el monto de la emisión y se comprometan a responder como avalistas. En todos los casos se ha de incurrir en costos que se miden en dinero relacionados con el estudio y la elaboración de documentos, así como los trámites de registro necesarios para perfeccionar la garantía que se utilice.

La situación patrimonial y el perfil del cliente que acude a las instituciones microfinancieras le impide hacer uso de las garantias tradicionales, razón por la cual, ampliar la cobertura a los desmovilizados los ubica en la necesidad de buscar otras garantías para tener acceso al microcrédito, en particular al Fondo Nacional de Garantías (FNG), ${ }^{65}$ organismo privado que, a cambio del pago de una comisión, garantiza créditos de la pequeña y mediana empresa con distintos productos: ${ }^{66}$ garantía empresarial multipropósito; garantía para microcrédito; garantía para lea-

63 Nestor Humberto Martínez Neira, Cátedra de Derecho Bancario Colombiano, Bogotá, Legis, 2004.

64 Circular Externa 100 de 1995 de la Superintendencia Bancaria, hoy Superintendencia Financiera de Colombia.

65 El FNG es una sociedad anónima creada mediante escritura pública 130 de febrero 16 de 1982 , otorgada ante la Notaría 32 del Círculo de Bogotá con aportes del Instituto de Fomento Industrial (IFI), la Corporación Financiera de Desarrollo y las diferentes seccionales de la Asociación Colombiana de Medianas y Pequeñas Industrias (Acopi). Desde su creación ha realizado cambios en su portafolio de servicios y ha obtenido un auge y posicionamiento que desde enero de 2003 se incorpora al sistema financiero colombiano con la expedición de la Ley 795 y lo somete a la inspección, vigilancia y control de la entonces Superintendencia Bancaria, hoy Superintendencia Financiera de Colombia. A nivel regional, el FNG promovió la creación de Fondos Regionales de Garantías (FRG) en Antioquia, Atlántico, Boyacá, Nariño, Norte de Santander, Risaralda, Santander, Tolima y Valle.

66 Tomado de http://www.fng.gov.co/empresarios/productos-tradicionales-de-garant\%C3\%ADa. Fecha de consulta: 14 de octubre de 2015 . 
sing financiero; garantía para cupos rotativos globales; garantía para corto plazo y programa de garantía individual para la creación de empresas.

El desmovilizado se encuentra excluido de la posibilidad de otorgar garantías tradicionales y de acceder a la garantía ofrecida por el FNG, dado que debe tener el carácter de microempresa, razón por la cual solo puede acceder a los mecanismos de reintegración económica diseñados por el Estado. En esa medida, se pone en evidencia que dentro del proceso de reintegración la ayuda del Estado es limitada y, cuando la ofrece, los apoyos suelen ser bajos. ${ }^{67}$

Aun cuando el desmovilizado encontrara la forma de otorgar las garantías exigidas por la IMF, estas encontrarán muy riesgoso perfeccionar las operaciones de crédito y prestar los servicios complementarios, ante los imprevistos que se presenten en la región del país a la que los funcionarios de la institución deban enfrentarse al hacer presencia en dicha zona. El reto de la IMF será diseñar y ejecutar una política de riesgo diferenciada frente a sus tradicionales clientes catalogados como microempresarios, además aprender a manejar clientes con un perfil diferente, para lo cual tendrá que identificar cuál es la metodología apropiada para acceder al financiamiento requerido para obtener la reintegración económica.

Dentro de las metodologías conocidas en el ámbito de las IMF para el otorgamiento de crédito se conocen tres: individual, metodologia para grupos solidarios y metodología de banca comunal.

La metodologia individual tiene como objetivo apoyar la sostenibilidad del microempresario a través de la prestación de un producto ajustado a las características del microempresario, con una atención personalizada, que garantice la relación a largo plazo. La tecnología se fundamenta en la recopilación y el análisis in situ de la información al cliente, a fin de determinar técnicamente la capacidad y voluntad de pago y sustentar apropiadamente la decisión de financiamiento. En tal sentido, la exigencia de garantías asume un rol secundario, transformándose en la segunda fuente de pago del crédito. ${ }^{68}$

La metodología para grupos solidarios, originada en Asia con el propósito de coadyuvar a las actividades económicas de los pobres en las zonas rurales y urbanas, se fundamenta en la formación de un grupo como un medio para canalizar pequeños préstamos, entrenamiento y otros servicios a esta población. Con base en esta metodología se busca promover el desarrollo al dirigir recursos a los más necesitados para incrementar su capacidad de forjar su propio futuro, esta es una manera de atender a la creciente población necesitada permitiéndole el acceso a programas sencillos y accesibles para que respondan a sus demandas y, a la vez,

67 Daryl Collins, Jonathan Morduch y Stuart Rutheford, op. cit., p. 20.

68 J. B. JORDAN y J. C. R. FERRAND, La situación, tendencias y posibilidades de las microfinanzas, Quito, Editorial Abya Yala, 2004. 
aprendan a administrar sus escasos recursos. ${ }^{69}$ Se utiliza la tecnología de crédito grupal, en esta se forman grupos de cuatro o cinco personas que residan en la misma localidad y se les otorga un crédito por grupo, y posteriormente se asigna a cada miembro del grupo un monto igual o distinto de ese único préstamo, según la capacidad de pago y la actividad que realice cada uno. El grupo tiene un coordinador que responde solidariamente por el préstamo junto a todos los miembros. A parte de los servicios financieros también ofrecen servicios no financieros, como por ejemplo: cursos de capacitación, talleres de planificación familiar, seguro de vida, etc. Estos servicios complementan la gestión del crédito. ${ }^{70}$

La metodología de banca comunal, ${ }^{71}$ propuesta en la década de los ochenta en Estados Unidos por John y Margarita Hatch, con la intención de crear un instrumento para realizar actividades generadoras de ingreso, promover el ahorro y facilitar el apoyo mutuo entre grupos de 30 a 50 personas, consideramos es la adecuada para que las IMF estudien los créditos para los desmovilizados. Esta tiene las siguientes características:

- La formalización de un grupo entre 20 a 40 personas a través de una asamblea, donde todos participan democráticamente y eligen un comité el cual será el que realizará funciones administrativas.

- Este banco funcionará como intermediario para otorgar los créditos a la población objeto, aquella que carece de oportunidades para obtener recursos financieros a través de los medios tradicionales (por ejemplo, la banca comercial, mesas de dinero, etc.).

- La captación de recursos del banco comunal puede ser por aporte inicial de los miembros (por ejemplo: 20\%), en calidad de ahorro, recibiendo así un pequeño beneficio. Pero también, el origen de los recursos puede ser por la transferencia en calidad de fondo por parte de un grupo de empresas privadas o por un ente gubernamental como estrategia de politica social.

- Los beneficiarios pueden optar por créditos sucesivos, con la posibilidad de que los montos sean mayores, siempre que cancelen en el tiempo previsto, o mejor aún, antes del vencimiento de su deuda.

- En general, los bancos comunales tienen entre sus programas promover el ahorro, se exige un porcentaje mínimo del monto otorgado.

- Como los bancos comunales son mecanismos de financiamiento no convencionales, tienen el inconveniente de que carecen de representación legal.

La estructura del negocio microfinanciero, conforme al funcionamiento actual del mercado, excluye implícitamente al desmovilizado; el diseño de productos específicamente para desmovilizados constituye el principal reto para la IMF. Encontra-

69 Centro Internacional de Formación Financiera (CIFF), Microfinanzas en países de la OCDE y en vías de desarrollo. Alcalá: Universidad Alcalá de Henares, 2014, p. 50.

70 Ibid.

71 Ibid. 
mos aquí un desafío a la lógica dominante en las IMF, un nuevo reto, un área en la que se pueden diseñar nuevos productos financieros o rediseñar los existentes con unas características especiales, junto a una cultura organizacional apta para el manejo de un cliente especial. El papel de las IMF en el posconflicto será no limitarse a otorgar créditos para proyectos productivos, deberá guiará sus esfuerzos a mejorar las condiciones del sujeto que hace transición a la vida en paz, para lo cual tendrá que considerar la zona geográfica, urbana o rural para construir un nuevo portafolio de servicios que contribuya al manejo del posconflicto.

El reto de las IMF se complementaría con el diseño de productos financieros orientados a los pobladores rurales, dado que es en esta zona donde puede encontrarse gran parte de las personas que han atendido el llamado del Estado a desmovilizarse y reincorporarse a la vida civil. En este diseño, las IMF deberán indicar cuáles son las actividades productivas, cuáles los servicios financieros y la forma de acercar tales servicios a las zonas rurales. Igualmente, reconocerán los obstáculos entre los potenciales clientes relacionados especialmente con la falta de habilidades de emprendimiento y de administración de negocios.

El origen de los recursos financieros para que las IMF extiendan su cobertura a los desmovilizados es asunto que merece especial atención. Usualmente, el cumplimiento de políticas públicas supone el uso de recursos públicos, excepcionalmente con recursos privados. La financiación de excombatientes hará necesarios fondos públicos nacionales, recursos financieros aportados por la comunidad internacional, a título de préstamos o de donaciones, que serían administrados por una entidad fiduciaria, creando un fondo fiduciario para la paz. ${ }^{72}$

En la creación de fondos para el manejo del conflicto existe un referente a nivel internacional conocido como Fondo Post Conflicto (PFC, por su sigla en inglés), creado por el Banco Mundial en 1997 para ayudar a los países en transición hacia la paz y al crecimiento económico. El fondo ofrece ayuda a través de donaciones a organizaciones no gubernamentales, autoridades de transición y organismos de la ONU. Se destacan los apoyos ofrecidos por el fondo a Filipinas (Fondo de Reconstrucción y Desarrollo de Mindanao - MRDF), el cual se destinó a la reconstrucción de Mindanao después del conflicto; la ayuda a la población desplazada en Colombia orientada al financiamiento de los esfuerzos para minimizar el riesgo de desplazamiento de la población debido al conflicto existente, la protección de la tierra y otros bienes de las personas desplazadas para posibilitarles el regreso a sus hogares; el proyecto piloto de desarrollo impulsado por la comunidad en Haití para apoyar esfuerzos de desarrollo comunitario en áreas rurales, respaldando actividades de acceso a infraestructura social y económica, identificación y categorización de necesidades colectivas de la población rural. De igual forma, se entregó una donación a Irak para el financiamiento de microcrédito destinado a viudas iraquíes afectadas por el conflicto, buscando mejorar los ingresos de las viudas en la ciudad de Diwaniyah. En este caso se les otorgan microcréditos para

72 Nombre dado al fondo por el señor Jairo Morales Nieto, invitado a Colombia en 2014 para el diseño de una estrategia posconflicto. 
que inicien su propio negocio, y se les capacita para que desarrollen y mejoren sus destrezas. ${ }^{73}$

En la forma de financiar proyectos los subsidios se suman a los créditos. Los subsidios no tienen mayor cabida en las microfinanzas ni en el microcrédito. Con este se pretende romper el círculo vicioso de la asistencia social que crea dependencia. Promover el progreso autónomo sin subsidios es parte de la esencia del microcrédito. ${ }^{74}$

Las estrategias financieras diseñadas para la transición hacia la paz no incluyen de manera expresa a las IMF, los esfuerzos han estado orientados a analizar oferta y demanda de recursos financieros requeridos. En ellas identificamos cuatro pilares: construcción de un marco legal e institucional para la paz, la construcción de un sistema de financiamiento para la paz; la construcción de un sistema de inversiones para la paz y la construcción de un sistema de seguimiento y evaluación. ${ }^{75}$

El modelo propone la creación de organismos encargados de la decisión, de la operación financiera y técnica, responsables de llevar a la práctica los acuerdos de paz y la implementación de la estrategia posconflicto; en segundo lugar, sugiere crear un fondo fiduciario para la paz que tenga plena responsabilidad en la gestión y administración de recursos financieros; en tercer lugar, propone crear planes y proyectos de inversión acordes con la población y con el territorio; y finalmente, el diseño de un modelo de evaluación de resultados que considere distintos factores tales como alineación de la estrategia con los acuerdos de paz y las expectativas de la sociedad; logro de objetivos y metas; economicidad y transparencia en el uso de recursos, y cambios en el bienestar de la población.

La estrategia ha de centrarse en las finanzas rurales que garanticen a excombatientes y víctimas volver a su entorno. Las IMF podrían colaborar con la política estatal de reinserción. Esta podría incluir un capital semilla con base en el cual se creen unidades de negocio productivo. El apoyo con créditos colocados por las

73 Tomado de http://www.bancomundial.org/temas/resenas/post-conflicto.htm. Fecha de consulta: 26 de septiembre de 2015. Otros apoyos en cifras son los siguientes: Afganistán: apoyo a la administración pública (US\$10 millones), empoderamiento de la comunidad (US\$42 millones), educación (US\$ 15 millones), infraestructura (US\$33 millones) y transporte (US\$ 108 millones). Estos proyectos complementan el Fondo Fiduciario para la Reconstrucción de US\$150 millones; financiamiento del programa en la República Democrática del Congo para aumentar la seguridad alimentaria, restituir la infraestructura y los servicios sociales esenciales y mejorar la capacidad del Gobierno para formular y ejecutar programas de desarrollo (de US\$454 millones); un programa regional adicional de US\$500 millones está apoyando la desmovilización y reintegración de excombatientes en los nueve países de la subregión de grandes lagos de África; apoyo a la reintegración de población desplazada en Azerbaiyán, Rwanda y Sierra Leona; préstamo de US\$31 millones para el programa de reconstrucción de emergencia en el noreste de Sri Lanka para restaurar centros de atención de salud primaria, facilitar el sustento a personas desplazadas que regresan a sus hogares a través de donaciones en efectivo y restaurar el suministro de agua a las aldeas; y finalmente, el apoyo a

30674 Catalina Rodríguez, "Impacto de las microfinanzas: resultados de algunos estudios. Énfasis en el sector financiero”, Ciencias estratégicas (2008), pp. 281-298.

75 Jairo Morales, "Posconflicto como estrategia financiera de la paz", El Espectador, 2 de mayo de 2015.

DÍKAION - ISSN 0120-8942 - EISSN 2027-5366 
IMF tendría lugar después de habilitar al reinsertado para trabajar, quien luego se someterá a evaluación como sujeto de crédito.

El nuevo enfoque de las finanzas rurales reconoce que los servicios financieros rurales no son solo créditos agrícolas, ellos pueden incluir otros servicios como remesas, seguros, jubilaciones, facilidades de depósito y acceso al crédito, seguros en distintos ramos, ${ }^{76}$ en general, productos innovadores para el sector rural, acordes con la zona geográfica, con las necesidades de la región y las aptitudes del desmovilizado que se beneficiará con estos servicios en la nueva fase de su vida de reintegro a la sociedad y al campo colombiano.

Independientemente del lugar de ubicación del desmovilizado las IMF, como orientadoras del crédito microempresarial con los recursos provenientes de los fondos, diseñarán productos financieros bajo la modalidad de préstamos con un monto, plazo y amortización acordes con el beneficiario, con su situación personal, con la actividad que realizará, con la región donde se halle ubicado; además, diseñará mecanismos para generar una cultura de pago en quien pretende transformarse en gestor de su futuro.

\section{FUNCIÓN SOCIAL DE LA ACTIVIDAD DESARROLLADA POR LAS IMF}

Las IMF en su rol de empresa, cuyas actividades se desarrollan en Colombia, tienen una función social que implica obligaciones. ${ }^{77}$ La labor de las empresas no puede orientarse exclusivamente al interés individual, porque tienen también una función social consistente en crear riqueza para la comunidad y promover el desarrollo integral; al lado del fin particular y lucrativo del empresario está el interés general o social. Por eso, a las empresas se les reconoció categoría sociológica o social desde cuando el socialismo y la doctrina social cristiana católica insistieron, con persistencia, en que la empresa es básicamente una categoría social. ${ }^{78}$

Este reconocimiento de categoría social impone unas cargas que las IMF en la actualidad cumplen con el microcrédito, producto que ofrecen con una amplia exposición al riesgo de incumplimiento, que de presentarse produce efectos en su patrimonio privado. Al asumir un riesgo de pérdida de los recursos que colocan en manos de personas con liquidez y solvencia bajas, y con el esfuerzo de ampliar su cobertura a regiones del país donde no llega la banca tradicional, estas entidades cumplen con el mandato constitucional de desempeñar una función social orientada hacia la democratización del crédito. ${ }^{79}$

76 Robert Vogel, "Del crédito agrícola a las finanzas rurales: en búsqueda de un nuevo paradigma", Experiencias y desafios en microfinanzas y desarrollo rural, Quito, Fraga, 2004.

77 Artículo 333 de la Constitución Política de Colombia.

78 José Ignacio NARVÁEz, Introducción al derecho mercantil, Bogotá, Doctrina y Ley, 1995.

79 La Corte Constitucional colombiana considera que se cumple con la función social cuando se amplía la oferta de servicios financieros, se democratiza el crédito y se fortalece el movimiento solidario. Si bien las IMF no forman parte del movimiento solidario, hacemos extensiva esta regla 
Esta función social podría ampliarse mediante una regulación que incluya a las IMF como organismos de apoyo del Estado, siempre y cuando su patrimonio no sufra los efectos del incumplimiento. Las IMF tendrían la carga operativa de evaluar y colocar los recursos monetarios que el Estado destine, y, además, cumplir con las cargas que en su condición de administradoras de recursos públicos se les impongan. La primera responsabilidad la tendrán una vez los reinsertados hayan recibido del Estado la capacitación que los habilite para trabajar, diseñar o ejecutar ideas de negocio. La segunda estará asociada a controlar la destinación de los recursos, recaudar las sumas prestadas y restituirlas al Estado en la época y forma que la regulación señale.

Bajo ese parámetro se verifica que la función social de la empresa presenta diversas y matizadas caracterizaciones, las cuales cambian según la naturaleza de los bienes, su clase, la entidad que es titular de los derechos y la posición económica y social que ocupan los sujetos vinculados a la empresa y los destinatarios de los beneficios sociales que reporta.

En cumplimiento de esta función social, las IMF tendrán en cuenta que su actividad no es solamente la prestación de servicios de crédito, su contribución al posconflicto se complementa con centrar su atención, además de los servicios financieros, en los servicios no financieros como programas de capacitación en educación financiera, creación de liderazgo, fomento de la cultura del emprendimiento, para lo cual podrian suscribir convenios con instituciones de educación formal e informal.

Finalmente, se reconoce que la responsabilidad para la paz, la seguridad y el desarrollo en Colombia corresponde al Estado, ${ }^{80}$ y que el sector privado, en este caso las IMF, tiene un papel importante como constructor de paz en el área geográfica donde desarrolla sus actividades.

Las actividades comerciales y de inversión pueden tener impactos positivos y negativos en los indicadores de violencia de un país o territorio y, a su vez, pueden generar riesgos financieros y en la capacidad operativa, por lo que puede verse mermada la reputación de la empresa. Así pues, la responsabilidad social de la empresa en contextos de conflicto armado deberá adaptarse a este tipo de entornos complejos y este requisito es válido tanto para empresas globales como pymes, empresas públicas como privadas, así como para empresas nacionales o extranjeras. La empresa debe, por tanto, conocer el contexto de conflicto en el que opera, así como sus actores, y adaptar su negocio y las relaciones con sus stakeholders desde una perspectiva de sensibilidad al conflicto. ${ }^{81}$

jurisprudencial a ellas. Pueden consultarse las sentencias C-779 de 2001 (M. P. Jaime Araújo Renteria), C-948 de 2001 (M. P. Clara Inés Vargas Hernández), C-188 de 2006 (M. P. Rodrigo Escobar Gil) y C-909 de 2012 (M. P. Nilson Pinilla Pinilla).

$308 \quad 80$ Artículo 2, Constitución Política de Colombia

81 Josep LozAno y María PRANDI, La RSE en contextos de conflicto y posconflicto: de la gestión del riesgo a la creación de valor, Lima, Escola de Cultura de Pau (UAB)/ Instituto de Innovación Social (Esade), 2010, p. 30 . 


\section{CONCLUSIONES}

Las IMF, independientemente de la modalidad que adopten, es decir, organizaciones no gubernamentales, entidades del sector solidario o bancos comerciales con productos y servicios para microempresas, pueden apoyar los procesos de construcción de paz que han sido iniciativa gubernamental, sin comprometer su patrimonio. Este apoyo les plantea distintos retos: administrar capital estatal, ampliar cobertura de sus productos o servicios con especial énfasis en las microfinanzas rurales, asumir una carga operativa nueva, diseñar mecanismos de administración de riesgos con componentes especiales derivados de la especial condición de los desmovilizados, diseñar estrategias de recuperación de cartera en zonas de difícil acceso, realizar campañas para creación de liderazgo, aprender a manejar clientes con un perfil especial, diseñar un régimen de garantías compartidas, administrar y colocar recursos estatales destinados para el manejo del posconflicto, y, de manera general, tener presente que la actividad de las IMF no solamente gira en torno al microcrédito.

Esta ampliación de cobertura mejorará sus indicadores de gestión dado que la cobertura es criterio que puede utilizarse para evaluar el desempeño de organizaciones que ofrecen una amplia gama de servicios financieros ${ }^{82}$ a un número elevado de clientes pobres, y puede ser medida por su amplitud, profundidad y calidad. La amplitud hace referencia a montos los desembolsados y el número de clientes atendidos; la profundidad indica el éxito alcanzado en superar las dificultades de llevarle servicios financieros a clientelas difíciles, y se mide por el tamaño promedio de los préstamos y por la distribución de la cartera con base en criterios socioeconómicos; y la calidad se mide por el nivel de los costos de transacción que se le imponen a los clientes y según lo apropiados que sean los términos de los contratos celebrados por quienes ofrecen servicios financieros. Si una organización logra diseñar un programa de microfinanzas con clientelas numerosas y en aumento será socialmente más atractiva. ${ }^{83}$

Independientemente de si el Estado las incluye en la regulación como organizaciones que faciliten el acceso a servicios financieros y no financieros para el manejo del posconflicto, la filosofia que inspira su existencia y creación, y la libertad que tienen para diseñar productos financieros, les permite disminuir los efectos del conflicto no solo en los desmovilizados, sino frente a las víctimas del conflicto armado. Su vinculación en este propósito de construcción de paz dependerá de incentivos que el Estado colombiano diseñe para compensar a estos particulares interesados en contribuir con la transformación del desmovilizado en un emprendedor, un creador de empresa, gestor de su progreso, que reconozca y valore el esfuerzo y apoyo que las instituciones públicas y privadas le ofrecen para mejorar sus condiciones de vida.

82 J. YARON, What makes rural finance institutions succesful? The World Bank Research Observer, 1994, pp. 49-70.

83 Claudio González, El reto de las microfinanzas en América Latina: la visión actual, Caracas, Corporación Andina de Fomento, 1997. 


\section{BIBLIOGRAFÍA}

Acosta, Mauricio, Experiencias de jóvenes excombatientes en proceso de reintegración a la vida civil en Bogotá D.C., Bogotá, Alcaldía Mayor de Bogotá, Fundación Friederich Eberth, Fescol, 2007.

ARCE, Jose Luis, Duodécimo informe sobre el estado de la nación en desarrollo humano sostenible, Costa Rica, 2012.

ARCE, Jose Luis, Centro Mundial de Investigación y Capacitación para la Resolución de Conflictos, 2010.

BAnco de la República, Situación actual del microcrédito en Colombia: características y experiencias, Bogotá, 2010.

Banco de la República, Informe Especial de estabilidad financiera, Bogotá, 2014.

Bucheli, Jordan, La situación, tendencias y posibilidades de las microfinanzas, Quito, Editorial Abya Yala, 2004.

Castillo Ramírez, Angie Juliet y Arlley Moreno Parga, La reintegración económica de personas desmovilizadas de grupos armados ilegales, como estrategia de superación de vulnerabilidades y desarrollo de capacidades, Bogotá, Uniminuto, 2013

CirfF, Centro.Internacional.Formación Financiera, MIcrofinanzas en países de la OCDE y en vías de desarrollo, Alcalá, Universidad Alcalá de Henares, 2014.

Collins, Daryl, Jonathan Morduch y Stuart Rutheford, Las finanzas de los pobres, México, Debate, 2011.

Comisión HistóRica del Conflicto y sus Víctimas, Contribución al entendimiento del conflicto armado en Colombia, Bogotá, 2015.

Consejo Nacional de Política Económica y Social, Documento Conpes 3554. Política Nacional de integración Económica y Social para Personas y Grupos Armados Ilegales, Bogotá, Conpes, 2008.

Estrada, Darío, Lisset Venegas y Paula Zuleta, Desarrollo económico, crédito rural y conflicto armado en Colombia, Bogotá, Citi Foundation, Finagro y Asomicrofinanzas, 2015.

González, Claudio, El reto de las microfinanzas en América Latina: la visión actual, Caracas, Corporación Andina de Fomento, 1997.

HeEn, Stacy, "The Role of microcredit in conflict and displacement mitigation: A case study in Cameroon", The Fletcher Journal of International Development (2004), pp. 31-50.

Herrera, Dylan y Paola GonzÁlez, "Estado del arte del DDR en Colombia frente a los estándares internacionales en DDR”, Colombia Internacional (2013), pp. 272-302.

310 JACOBSON, Jessica, Uganda: The provision of microfinance in the wake of conflict, Baltimore, Jhon Hopkins University Press, 2001. 
LoEwenthal, Arno, "Tendencias y benchmarking comparativo de las microfinanzas en Ecuador y latinoamérica”, en Usaid, Ecuador: moviendo fronteras en microfinanzas, Quito, Development Altenatives Inc, 2006, pp. 17-24.

LoPEz, Luis Fernando, "Desarrollo internacional microfinanciero”, Contexto (2000), pp. 29-36.

LozAno, Josep y María PRANDI, La RSE en contextos de conflicto y posconflicto: de la gestión del riesgo a la creación de valor, Lima, Escola de Cultura de Pau (UAB)/ Instituto de Innovación Social (ESADE), 2010.

Martínez Neira, Néstor Humberto, Cátedra de Derecho Bancario Colombiano, Bogotá, Legis, 2004.

Morales, Jairo, "Posconflicto como estrategia financiera de la paz", El Espectador, 2 de mayo de 2015 .

NARVAEZ, Jose Ignacio, Introducción al derecho mercantil, Bogotá: Doctrina y Ley, 1995.

Rodríguez, Catalina, "Impacto de las microfinanzas: resultados de algunos estudios. Énfasis en el sector financiero”, Ciencias estratégicas (2008), pp. 281-298.

Tucker, John, Microfinance development in Liberia, Liberia, United Nations Capital Development Fund (UNCDF), 2004, en http://www.microfinancegateway.org/ sites/default/files/mfg-en-paper-microfinance-development-in-liberia-an-initial-assessment-2004.pdf. Fecha de consulta: 6 de mayo de 2015.

Vogel, Robert, "Del crédito agrícola a las finanzas rurales: en búsqueda de un nuevo paradigma”, Experiencias y desafios en microfinanzas y desarrollo rural, Quito,Fraga, 2004.

WILson, Tamsin, Microfinance during and after armed conflict: Lesson from Angola, Cambodia, Mozambique and Ruanda, Springfield, Springfield Centre for Business, 2002, en http://www.springfieldcentre.com/wp-content/ uploads/2012/10/sp0202.pdf. Fecha de consulta: 5 de mayo de 2015.

YARON, Jacob, What makes rural finance institutions succesful? The World Bank Research Observer, 1994, pp. 49-70.

Yunus, Muhammand, Un mundo sin pobreza, Barcelona, Paidós, 2008.

\section{REGULACIÓN COLOMBIANA CONSULTADA}

\section{Código Civil.}

Código de Comercio.

Constitución Politica de Colombia.

Circular Externa 050 de 2001 de la Superintendencia Financiera de Colombia.

Decretos: 240 y 2560 de 1983; 468 de 1990; 663 de 1993; 128, 3360 de 2003;

1262 y 2767 de 2004; 4327 de 2005; 3043 y 3078 de 2006; 395 de 2007. 
Documento Conpes 3554: Politica nacional de reintegración social y económica para personas y grupos armados ilegales. Versión aprobada de diciembre 1 de 2008.

Leyes: 418 de 1997; 79 de 1998; 548 de 1999; 782 de 2002; 795 de 2003; 1106 de 2006; 1266 de 2008; 1676 de 2013.

\section{PLANES DE DESARROLLO}

Plan Nacional de Desarrollo 2006-2010, "Estado comunitario para todos". Plan Nacional de Desarrollo 2010-2014, "Prosperidad para todos". Plan Nacional de Desarrollo 2014-2018, "Todos por un nuevo país”.

\section{SENTENCIAS CoRTE Constitucional De Colombia}

C-225 de mayo 18 de 1995, M. P. Alejandro Martínez Caballero.

C-779 de 2001, M. P. Jaime Araújo Rentería.

C-948 de 2001, M. P. Clara Inés Vargas Hernández.

C-188 de 2006, M. P. Rodrigo Escobar Gil.

C-909 de 2012, M. P. Nilson Pinilla Pinilla.

\section{SITIOS WEB CONSULTADOS}

http://www.bancomundial.org/temas/resenas/post-conflicto www.bancosol.com.bo

www.finagro.com.co 